\title{
Ion-beam synthesis of amorphous SiC films: Structural analysis and recrystallization
}

\author{
C. Serre, L. Calvo-Barrio, A. Pérez-Rodríguez,, a) A. Romano-Rodríguez, \\ and J. R. Morante \\ E. M. E., Departament de Física Aplicada i Electrònica, Universitat de Barcelona, Avda. Diagonal 645- \\ 647, 08028 Barcelona, Spain \\ Y. Pacaud, R. Kögler, V. Heera, and W. Skorupa \\ Forschungszentrum Rossendorf e.V., Institut für Ionenstrahlphysik und Materialforschung, Postfach 510119, \\ D-01314 Dresden, Germany
}

(Received 27 September 1995; accepted for publication 15 January 1996)

\begin{abstract}
The analysis of $\mathrm{SiC}$ films obtained by carbon ion implantation into amorphous $\mathrm{Si}$ (preamorphized by Ge ion implantation) has been performed by infrared and Raman scattering spectroscopies, transmission electron microscopy, Rutherford backscattering, and x-ray photoelectron spectroscopy (XPS). The data obtained show the formation of an amorphous $\mathrm{Si}_{1-x} \mathrm{C}_{x}$ layer on top of the amorphous $\mathrm{Si}$ one by successive $\mathrm{Ge}$ and $\mathrm{C}$ implantations. The fitting of the XPS spectra indicates the presence of about $70 \%$ of $\mathrm{Si}-\mathrm{C}$ bonds in addition to the $\mathrm{Si}-\mathrm{Si}$ and $\mathrm{C}-\mathrm{C}$ ones in the implanted region, with a composition in the range $0.35<x<0.6$. This points out the existence of a partial chemical order in the layer, in between the cases of perfect mixing and complete chemical order. Recrystallization of the layers has been achieved by ion-beam induced epitaxial crystallization (IBIEC), which gives rise to a nanocrystalline $\mathrm{SiC}$ layer. However, recrystallization is not complete, observing still the presence of $\mathrm{Si}-\mathrm{Si}$ and $\mathrm{C}-\mathrm{C}$ bonds in an amorphous phase. Moreover, the distribution of the different bonds in the IBIEC processed samples is similar to that from the as-implanted ones. This suggests that during IBIEC homopolar bonds are not broken, and only regions with dominant $\mathrm{Si}-\mathrm{C}$ heteropolar bonds recrystallize. (C) 1996 American Institute of Physics. [S0021-8979(96)09508-6]
\end{abstract}

\section{INTRODUCTION}

$\mathrm{SiC}$ is a wide band-gap semiconductor which has been receiving much interest in the last few years, due to its potential for high temperature, power electronic, and sensor applications. ${ }^{1-4}$ The development of this potential strongly requires to solve different technological problems related to its processing. One of the main drawbacks is the very high stability of $\mathrm{SiC}$ regions amorphized during processing. Recrystallization of amorphized $\mathrm{SiC}$ requires very high temperature anneals, of the order of $1500{ }^{\circ} \mathrm{C}^{5-7}$ To avoid this problem, the use of ion-beam induced epitaxial crystallization (IBIEC) has been recently studied. ${ }^{8}$ Heera et al. have reported the recrystallization of $6 \mathrm{H}-\mathrm{SiC}$ wafers amorphized by $\mathrm{Ge}^{+}$ion implantation by the use of $\mathrm{Si}^{+}$ion implantation at temperatures as low as $480{ }^{\circ} \mathrm{C} .{ }^{8}$ However, in this work recrystallization is not complete, being the regrowth process stopped by polynucleation near the surface region. To clarify the mechanisms involved, further experiments are needed, including the analysis of amorphous layers obtained by different processes.

On the other hand, amorphous $\mathrm{SiC}$ films have interest related to their high hardness and optical properties, and have potential applications as hard, wear resistant coatings, masking material in Si micromachining technology, as well as for the formation of optical windows, filters, and color sensors. ${ }^{3,9}$ More recently, the differences between the thermal conductivity and optical properties of amorphous and

${ }^{\text {a)} E l e c t r o n i c ~ m a i l: ~ p e r e z-r o @ i r i s 1 . f a e . u b . e s ~}$ crystalline $\mathrm{SiC}$ have been proposed to be used for the design and development of sensors combining both amorphous and crystalline phases. ${ }^{10}$

The exploitation of all these possibilities strongly requires a better knowledge of the structural characteristics of amorphous $\mathrm{SiC}$ and its dependence on the processing parameters. An important point related to the stability of this phase and its recrystallization behavior is the local bonding configuration and the degree of chemical order of the material. This is determined by the different characteristics of the possible bonds involved (bond length and energy).

For a fourfold coordinated amorphous $\mathrm{A}_{1-x} \mathrm{~B}_{x}$ binary system, three different limiting cases of chemical arrangement can be observed: (i) a complete phase separation, (ii) a perfect mixing and (iii) a complete chemically ordered material. ${ }^{11-13}$ In the first case, only homonuclear A-A and B-B bonds are observed, with probabilities $(1-x)$ and $x$, respectively. The second case corresponds to the absence of chemical order, in which a random distribution of bonds occurs. Accordingly, the probabilities of the different bonds are given by $(1-x)^{2}(\mathrm{~A}-\mathrm{A}), 2 x(1-x)(\mathrm{A}-\mathrm{B})$ and $x^{2}(\mathrm{~B}-\mathrm{B})$. In the third case, a maximum concentration of heteronuclear bonds is observed, due to its higher stability. In this case, the relative concentration of the different bonds depends on the value of $x$, as all the minority atoms are heterobonded. For $x<0.5$ (A rich material), the probabilities of occurrence of the bonds are $1-2 x(\mathrm{~A}-\mathrm{A}), 2 x(\mathrm{~A}-\mathrm{B})$, and $0(\mathrm{~B}-\mathrm{B})$. For $x>0.5$ (B rich material), these are given by $0(\mathrm{~A}-\mathrm{A}), 2(1$ $-x)(\mathrm{A}-\mathrm{B})$, and $2 x-1$ (B-B). Accordingly, the study of the chemical structure and coordination of the layer requires 
the analysis of samples of different composition.

Different authors have reported the structural analysis of amorphous $\mathrm{SiC}$ layers obtained by different techniques, including chemical vapor deposition, glow discharge, and sputtering. ${ }^{12-19}$ These works have involved the use of different techniques such as x-ray scattering, extended x-ray absorption fine structure, $\mathrm{x}$-ray photoelectron spectroscopy, Auger electron spectroscopy, Raman scattering, and infrared spectroscopy, observing a strong dependence of the chemical ordering and crystalline structure of the layers on the deposition conditions. Moreover, some of the experimental results are still not clear, being the subject of controversy.

In this work, the structural analysis of amorphous $\mathrm{SiC}$ films obtained by ion-beam synthesis is reported. In contrast with previous works, amorphous $\mathrm{SiC}$ layers have been obtained by high dose carbon implantation into previously amorphized Si films. In relation to the other techniques of producing amorphous $\mathrm{SiC}$, ion implantation has the advantage of allowing the formation of an amorphous $\mathrm{Si}_{1-x} \mathrm{C}_{x}$ layer of gradual composition in a straightforward way. Then, the in-depth analysis of the implanted samples allows their study as a function of the chemical composition.

The analysis of the layers has been performed by optical (infrared and raman spectroscopies) and structural (Rutherford backscattering (RBS), transmission electron microscopy (TEM)) techniques. The chemical composition and structure of the implanted layers have been investigated by $\mathrm{x}$-ray photoelectron spectroscopy (XPS). In-depth XPS measurements have been performed, allowing to study the evolution of the different bond configurations with the carbon content. The data obtained from the implanted layers have been correlated with those from similar samples which were recrystallized by the IBIEC process.

\section{EXPERIMENTAL DETAILS}

(100) $\mathrm{Si}$ wafers were implanted with $5 \times 10^{14} \mathrm{Ge}^{+}$ ions $/ \mathrm{cm}^{2}$ at an energy of $200 \mathrm{keV}$. During implantation, the wafers were cooled to keep them close to room temperature. This implantation produced an amorphous Si surface layer, about $175 \mathrm{~nm}$ thick, as observed by RBS and TEM.

Subsequently, part of these wafers was implanted with carbon at an energy of $25 \mathrm{keV}$ and a dose of $4 \times 10^{17}$ $\mathrm{cm}^{-2}$. This implantation was also performed at room temperature. According to the transport of ions in matter (TRIM) simulation, ${ }^{20}$ this dose is above the threshold, which is defined as the minimum dose for which stoichiometric composition is reached at the implanted peak.

Recrystallization of the amorphous surface layer was performed by $\mathrm{Si}$ irradiation at $700{ }^{\circ} \mathrm{C}$, with an energy of 300 $\mathrm{keV}$ and a dose of $10^{17} \mathrm{~cm}^{-2}$. Only part of the samples was irradiated with $\mathrm{Si}$. The part of the samples which was not irradiated has been analyzed in order to determine the effects of the thermal annealing at $700{ }^{\circ} \mathrm{C}$ on the amorphous layer. Samples obtained after each processing step have been analyzed. In the following, the different samples are referred to as the carbon as-implanted, thermally annealed, and IBIEC processed ones.

Fourier transform infrared (FTIR) measurements were performed with a BOMEM DA3 spectrometer. The spectra were measured in vacuum at room temperature using normal incidence. The absorption spectra from the carbon implanted regions of the samples were extracted by using as reference spectra those measured in the samples which were not implanted with carbon.

Raman scattering measurements were performed in backscattering configuration with a Jobin-Yvon T64000 spectrometer coupled with an Olympus metallographic microscope. To analyze the different $\mathrm{Si}-\mathrm{Si}, \mathrm{Si}-\mathrm{C}$, and $\mathrm{C}-\mathrm{C}$ related modes, the spectra were measured in the broad spectral region between 50 and $1800 \mathrm{~cm}^{-1}$. Excitation was provided by an $\mathrm{Ar}^{+}$laser operating at a wavelength of 457.9 $\mathrm{nm}$. Excitation power density on the samples was kept below $0.75 \mathrm{MW} / \mathrm{cm}^{2}$. Previous measurements performed at different excitation powers allowed us to observe the absence of thermal effects in the spectra for the values employed in this study.

XPS measurements were carried out with a PerkinElmer PHI 5500 spectrometer using $\mathrm{MgK} \alpha$ radiation. Indepth XPS data were obtained by measuring the spectra after sputtering the samples to different thicknesses with an $\mathrm{Ar}^{+}$ ion beam at $4 \mathrm{keV}$. For the measuring conditions, the full width at half maximum (FWHM) of the $\mathrm{Ag} 3 d_{5 / 2}$ line was $1.5 \mathrm{eV}$. In principle, some changes of the structure and composition of the surface region could be expected after Ar sputtering, due to preferential sputtering. However, Pezoldt et $a .^{21}{ }^{21}$ have observed these effects to depend on the sputter energy, reporting similar surface and bulk compositions in $\mathrm{SiC}$ for the energy used in this work $(4 \mathrm{keV})$. According to these data, no significant sputtering effects are to be expected in the XPS measurements.

Pieces from the different samples have also been observed by cross-section TEM using a Philips CM30 SuperTwin microscope, operated at $300 \mathrm{keV}$. Finally, the structural analysis of the samples has been completed by Rutherford backscattering random and channeling measurements using $1.7 \mathrm{MeV} \mathrm{He}^{+}$ions.

\section{RESULTS}

\section{A. FTIR and Raman spectra}

Figure 1 shows the FTIR spectra measured in the different samples, together with their fitting with Gaussian and Lorentzian curves. As it is shown, the spectrum from the carbon as-implanted sample is characterized by a broad absorption band, Gaussian in shape, centered at about 737 $\mathrm{cm}^{-1}$ and with a FWHM of $300 \mathrm{~cm}^{-1}$. This corresponds to the $\mathrm{Si}-\mathrm{C}$ related absorption band, and indicates the presence of $\mathrm{Si}-\mathrm{C}$ bonds in an amorphous phase after implantation. ${ }^{22}$ Annealing this sample at $700{ }^{\circ} \mathrm{C}$, a Lorentzian contribution $\left(\omega_{0}=795 \mathrm{~cm}^{-1}, \mathrm{FWHM}=48 \mathrm{~cm}^{-1}\right)$ appears in addition to the Gaussian band. This indicates a certain thermal recrystallization of $\mathrm{SiC}$. From the ratio between the amorphous (Gaussian) and crystalline (Lorentzian) contributions, about $10 \%$ of amorphous $\mathrm{SiC}$ is estimated to recrystallize. For the IBIEC processed sample, no Gaussian signal is observed at all, and only the Lorentzian signal from crystalline $\mathrm{SiC}$ ap- 


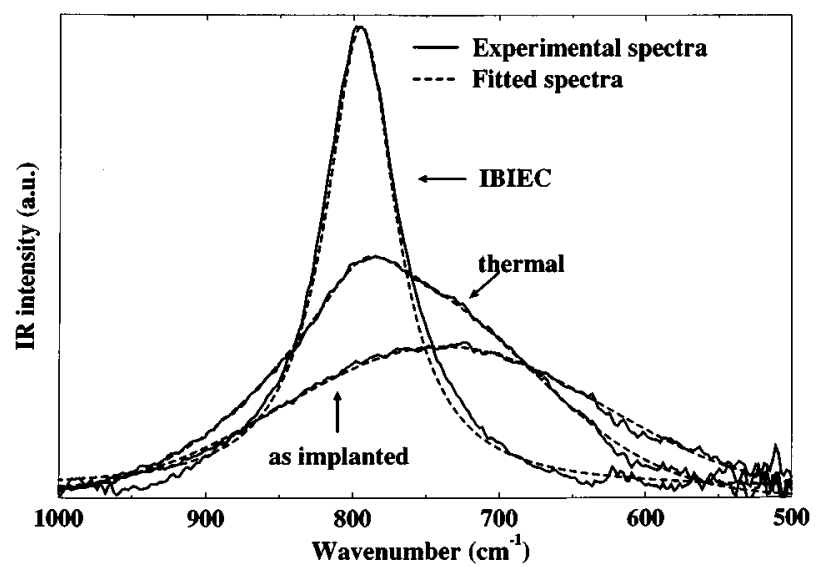

FIG. 1. Infrared absorbance spectra from the samples as-implanted, thermally annealed, and IBIEC processed, together with their fitting (dashed lines).

pears. Moreover, the different spectra present a similar area, which suggests that all the samples have the same amount of $\mathrm{Si}-\mathrm{C}$ bonds. The small FWHM of the spectrum from the IBIEC processed sample indicates a strong crystallization of the $\mathrm{SiC}$ layer by the IBIEC process.

The Raman spectra from these samples are characterized by the presence of bands characteristic of amorphous material, in the $50-600 \mathrm{~cm}^{-1}$ and $1300-1600 \mathrm{~cm}^{-1}$ spectral regions. This can be seen in Fig. 2, where the spectra measured in these regions from the carbon as-implanted and IBIEC processed samples are plotted. The spectra measured from the thermally annealed sample (not shown) are similar to those from the carbon as-implanted one. These bands are similar to those reported for amorphous $\mathrm{Si}_{1-x} \mathrm{C}_{x}$ films obtained by different techniques ${ }^{13,21,23}$ and have been interpreted according to a three-mode behavior, related to the different $\mathrm{Si}-\mathrm{Si}, \mathrm{Si}-\mathrm{C}$, and $\mathrm{C}-\mathrm{C}$ vibrational modes. So, the first bands are similar to the TA and TO ones from amorphous $\mathrm{Si}$ (at about 160 and $480 \mathrm{~cm}^{-1}$ ). The measurements reported for amorphous $\mathrm{Si}_{1-x} \mathrm{C}_{x}$ alloys indicate that as the carbon content increases, the frequency of the acoustic-like band increases, and the TO band is distorted. This is inter-

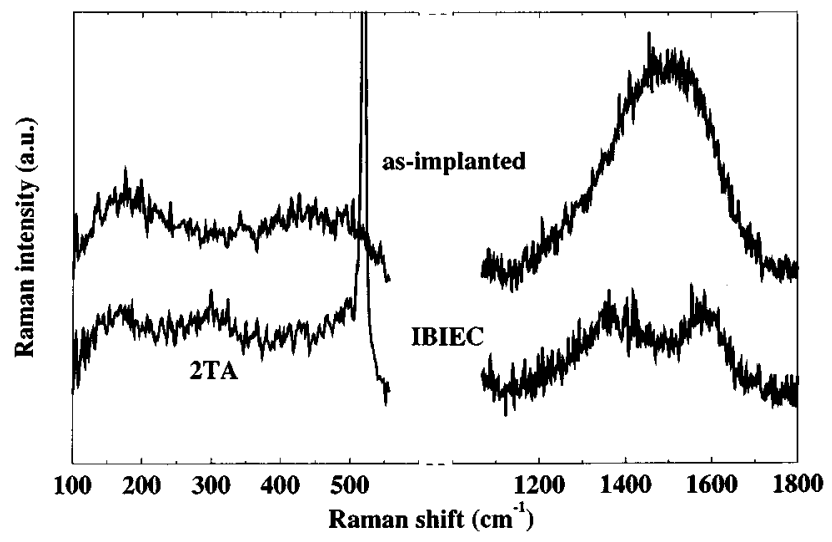

FIG. 2. Raman spectra in the $100-600$ and $1200-1800 \mathrm{~cm}^{-1}$ spectral regions from the samples as-implanted and IBIEC processed. (a)

(b)

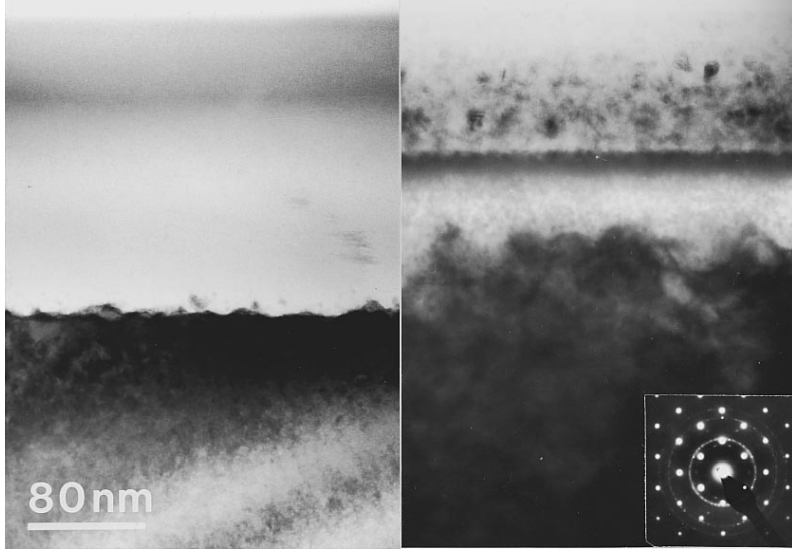

FIG. 3. Cross-section TEM image from the samples as-implanted (a) and IBIEC processed (b). The inset is a diffraction pattern from the $\mathrm{SiC}$ and $\mathrm{Si}$ areas in (b).

preted as related to $\mathrm{Si}-\mathrm{Si}$ vibrational modes, which are affected by the presence of $\mathrm{C}$ atoms in the film. Moreover, changes in the medium frequency region are related to the contribution of $\mathrm{Si}-\mathrm{C}$ related modes. Accordingly, although no band directly related to $\mathrm{Si}-\mathrm{C}$ vibrational modes is observed, the presence of $\mathrm{Si}-\mathrm{C}$ bonds is deduced from the changes of the $\mathrm{Si}-\mathrm{Si}$ modes in relation to the spectrum from amorphous silicon. Moreover, the band appearing in the $1300-1600 \mathrm{~cm}^{-1}$ spectral region is related to $\mathrm{C}-\mathrm{C}$ vibrational modes. The presence of this band, together with those related to the $\mathrm{Si}-\mathrm{Si}$ bonds, agrees with the previous observation by FTIR of amorphous $\mathrm{SiC}$ in the carbon as-implanted sample.

For the IBIEC processed sample, there is a decrease in the intensity of the amorphous bands. Moreover, the spectrum also shows the presence of the first and second order (2TA) peaks from the crystalline Si substrate (at 520 and 302 $\mathrm{cm}^{-1}$, respectively). This is due to the smaller optical absorption of the crystalline $\mathrm{SiC}$ in relation to the amorphous phase, and to the recrystallization of the Si region below the implanted layer (as will be shown in the next section). However, Raman spectra still show amorphous bands. This indicates the presence of residual amorphous material in the IBIEC processed sample, in spite of the FTIR data. Moreover, the $\mathrm{C}-\mathrm{C}$ spectrum shows a double band centered at 1380 and $1590 \mathrm{~cm}^{-1}$. This is very similar to the spectra reported for amorphous graphitic carbon, ${ }^{13,22}$ and has been recently simulated for amorphous carbon with $s p^{2}$ coordination. All this strongly suggests $\mathrm{C}-\mathrm{C}$ bonds in the amorphous material to be in $s p^{2}$ coordination. For the as-implanted sample, the shape of the $\mathrm{C}-\mathrm{C}$ band suggests a mixed $s p^{2}-s p^{3}$ coordination, being the band centered at energies between those simulated for both coordinations.

\section{B. TEM and RBS data}

Figure 3(a) corresponds to the cross-section TEM image of the as-implanted sample. As shown in this figure, there are two different amorphous regions on the crystalline $\mathrm{Si}$ substrate, the top darker one-about $90 \mathrm{~nm}$ thick-corre- 
sponding to the carbon implanted layer. An even darker band appearing in this region at a depth of about $60 \mathrm{~nm}$ corresponds to the carbon implantation peak. Moreover, a darker band can also be observed at the surface. This suggests the presence of a higher carbon content at the surface of the sample. Between the amorphous carbon implanted layer and the crystalline substrate, an amorphous Si region is observed. This is the second amorphous region in Fig. 3(a).

TEM observation of the thermally annealed sample (not shown) corroborates the recrystallization of the lower amorphous Si region. However, recrystallization stops at the carbon implanted amorphous layer. Moreover, a high density of end-of-range defects is observed at the original amorphous/ crystalline interface.

For the IBIEC processed sample [see Fig. 3(b)] the implanted layer also recrystallizes, observing $\mathrm{SiC}$ nanocrystalline grains. The electron diffraction pattern from this region [inset in Fig. 3(b)] shows the presence of rings corresponding to the randomly oriented $\mathrm{SiC}$ grains, in addition to the $\mathrm{Si}$ spots. The size of the grains changes with depth, observing larger grains in the central region corresponding to the carbon implantation peak, with sizes of about $10-20 \mathrm{~nm}$. Below this layer, crystalline $\mathrm{Si}$ is observed. This appears heavily damaged, due to the Si irradiation performed during IBIEC.

RBS data indicate the complete recrystallization of the amorphous layer at $700{ }^{\circ} \mathrm{C}$ when carbon is not implanted. For the carbon implanted and thermally annealed sample, only the $\mathrm{Si}$ amorphous region below the carbon implanted one recrystallizes. So, the yield in this region of the RBS channeling spectrum in Fig. 4(a) is lower than the random one (as simulated by RUMP ${ }^{24}$ ). For the carbon implanted layer the RBS channeling yield reaches the random spectrum simulated by RUMP, showing its amorphous nature. This yield is much lower than in the second ( $\mathrm{Si}$ ) amorphous region because of the high content of C. Accordingly, for the thermally annealed sample epitaxial crystallization stops when the recrystallization front reaches the carbon implanted tail, in agreement with the TEM data.

As shown in Fig. 4(a), the RBS spectrum of the IBIEC processed sample is very similar to that from the thermally annealed one. This is due to the polycrystalline nature of the recrystallized layer, for which the random yield is achieved. However, in this case the crystal quality in the Si region below the polycrystalline layer is much better, especially at the original amorphous/crystalline interface.

The carbon profiles deduced from RBS are shown in Fig. 4(b) [where the Si background has been subtracted]. Clearly, a carbon surface peak is observed in the as-implanted sample, indicating an accumulation of carbon at the surface, as suggested by TEM. Obviously this accumulation at the surface is not so clear for the IBIEC processed sample.

\section{XPS analysis}

The distribution of the carbon implanted ions has been investigated by measuring the $\mathrm{Ar} 2 p, \mathrm{C} 1 s, \mathrm{Si} 2 p$, and $\mathrm{O}$ $1 s$ spectra in samples sputtered with the $\mathrm{Ar}^{+}$beam at different depths. In all the samples, the Ar spectra measured at different depths always show the same shape and position. This indicates the absence of charge effects during these
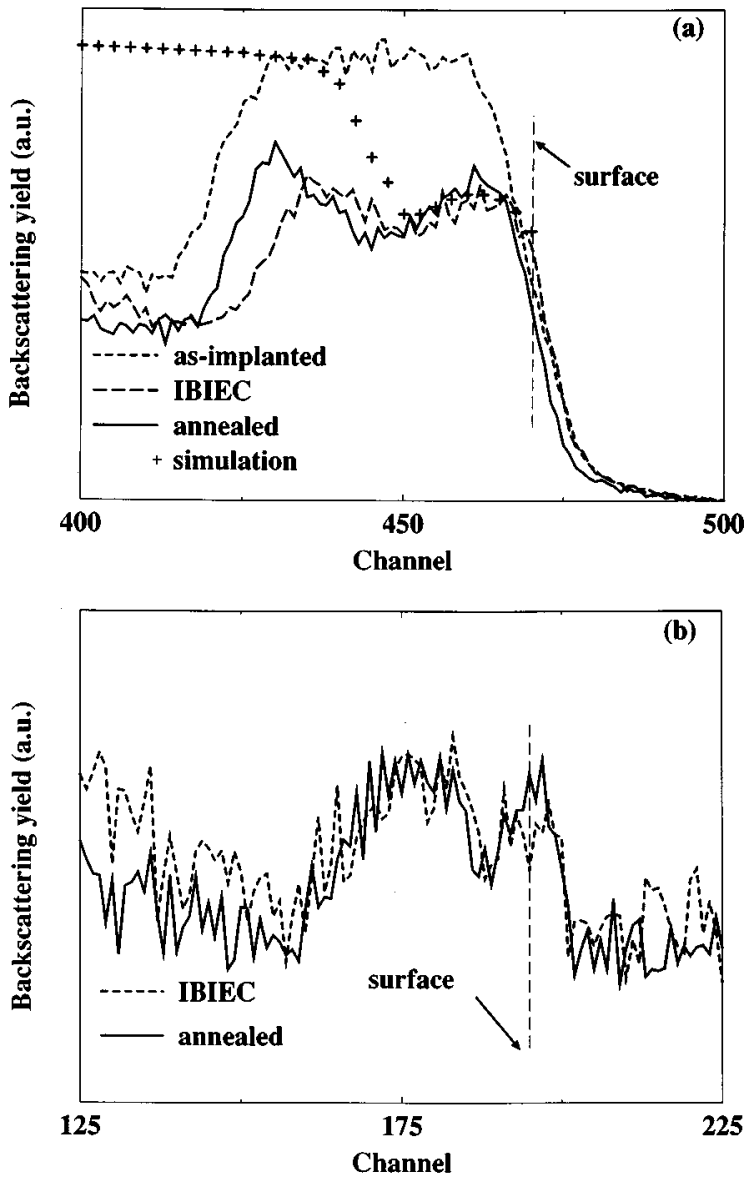

FIG. 4. (a) RBS spectra from the samples amorphized by Ge implantation (as-implanted), C implanted and thermally annealed, and IBIEC processed. The random spectrum calculated by RUMP [24] for the C as-implanted sample is also shown. (b) Carbon profiles from RBS from the thermally annealed and IBIEC processed samples.

measurements in the implanted layers. Moreover, no significant oxygen contribution has been measured, except at the surface due to the native surface oxide and surface contamination.

The silicon and carbon concentration profiles from the carbon as-implanted sample are plotted in Fig. 5, as measured from the area of the $\mathrm{Si} 2 p$ and $\mathrm{C} 1 s$ peaks after their baseline correction and taking into account their different sensitivity factors. In agreement with TEM and RBS measurements, a surface carbon peak appears. At the buried implanted region, there is a maximum content of carbon of about $55 \%$. This agrees with the fact that the implantation dose was above the threshold value for stoichiometric concentration.

The silicon and carbon profiles after IBIEC processing are also plotted in Fig. 5. These profiles are very similar to those from the as-implanted sample. The main change is the decrease of the surface carbon peak. The presence in the as-implanted sample of this peak is similar to the results obtained from high-dose carbon ion implanted crystalline $\mathrm{Si}^{25}$ where a surface carbon peak is observed when the implantation is performed at room temperature. This has been interpreted as due to carbon migration and gettering at the surface. At higher implantation temperatures, this mecha- 


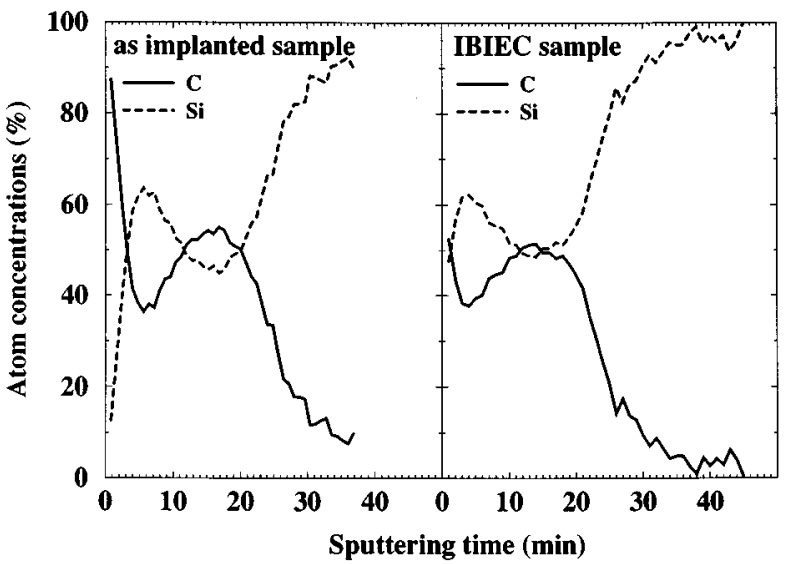

FIG. 5. Silicon and carbon profiles as measured by XPS vs sputter time from the carbon as-implanted and IBIEC processed samples. Etching rates were $3.5 \mathrm{~nm} / \mathrm{min}$ (as-implanted) and $4.3 \mathrm{~nm} / \mathrm{min}$ (IBIEC processed).

nism is inhibited due to the synthesis of crystalline $\beta$-SiC precipitates at the implanted peak.

\section{DISCUSSION}

The analysis of the carbon as-implanted sample shows the formation of an amorphous $\mathrm{SiC}$ layer on the Si substrate by the carbon ion implantation. So, FTIR and Raman spectra show the presence of bands characteristic of amorphous material, related to the different $\mathrm{Si}-\mathrm{C}, \mathrm{Si}-\mathrm{Si}$, and $\mathrm{C}-\mathrm{C}$ bond units.

On the other hand, the $\mathrm{C} 1 s$ and $\mathrm{Si} 2 p$ XPS spectra measured in the samples at different depth show changes in their shape and energetic position, in addition to the changes in the peak area. This indicates the existence of changes in the chemical environment of both $\mathrm{Si}$ and $\mathrm{C}$ atoms in the implanted layer, determined by the presence of the different $\mathrm{Si}-\mathrm{C}, \mathrm{C}-\mathrm{C}$, and $\mathrm{Si}-\mathrm{Si}$ bonds.

The quantification of the different bond contributions has been performed by the fitting of the XPS spectra. For this, Si $2 p$ spectra have been fitted with two Gaussian-like components, indicated in Table I. The first component corresponds to that measured in silicon reference wafers, as well as in the Si crystalline substrate far from the implanted region. The second component agrees with those reported for stoichiometric SiC. ${ }^{9,14,19,26}$ According to these data, the first component has been assigned to $\mathrm{Si}$ atoms bonded to $\mathrm{Si}$, and the second one to $\mathrm{Si}$ atoms bonded to $\mathrm{C}$. In a similar way, the $\mathrm{C}$ $1 s$ spectra have been fitted assuming the $\mathrm{C}-\mathrm{Si}$ and $\mathrm{C}-\mathrm{C}$ contributions indicated in Table II. These correspond to the

TABLE I. Peak position and FWHM (in eV) of the Gaussian components of the XPS Si $2 p$ spectra.

\begin{tabular}{crc}
\hline \hline Bond contribution & Peak & FWHM \\
\hline $\mathrm{Si}-\mathrm{Si}$ & 99.3 & 1.5 \\
$\mathrm{Si}-\mathrm{C}$ & 100.2 & 1.5 \\
\hline \hline
\end{tabular}

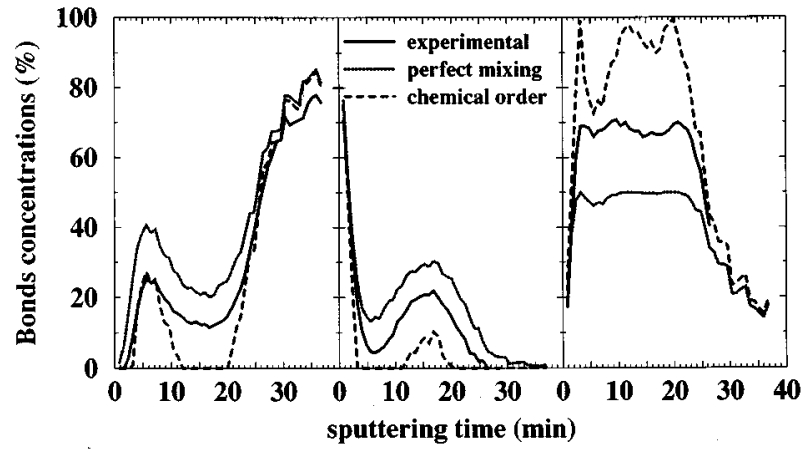

FIG. 6. Relative distribution profiles of $\mathrm{Si}-\mathrm{Si}, \mathrm{C}-\mathrm{C}$, and $\mathrm{Si}-\mathrm{C}$ bonds in the carbon as-implanted sample vs sputter time, determined from the fitting of the XPS spectra and simulated assuming the perfect mixing and complete chemically ordered cases.

spectra measured in $\mathrm{SiC}$ and amorphous carbon layers, in agreement with the data previously reported in the literature. ${ }^{9,14,19,26}$

Figure 6 shows the distribution of the different $\mathrm{Si}-\mathrm{Si}$, $\mathrm{C}-\mathrm{C}$, and $\mathrm{Si}-\mathrm{C}$ bonds in the carbon as-implanted layer, as determined from the fitting of the XPS spectra. As expected, the same amount of $\mathrm{Si}-\mathrm{C}$ bonds is obtained from the fitting of the Si $2 p$ and the C $1 s$ peaks. According to Fig. 6, about $70 \%$ of bonds are $\mathrm{Si}-\mathrm{C}$, being this value almost constant in the carbon implanted region. In these figures are also plotted the bond distributions simulated assuming a perfect mixing model and a complete chemically ordered structure. As shown, the structure of the implanted layers does not correspond to any of these theoretical simple models, being in all the cases the bond concentration profiles in between those predicted by the perfect mixing and complete chemically ordered cases.

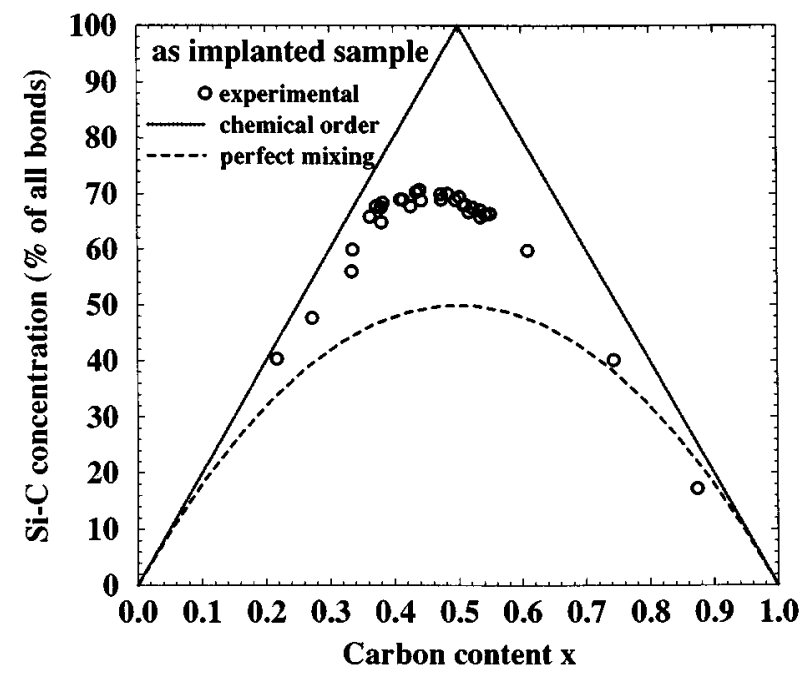

FIG. 7. Percentage of heteropolar bonds vs chemical composition $x$ of the $\mathrm{Si}_{1-x} \mathrm{C}_{x}$ alloy in the carbon as-implanted sample, as determined from the fitting of the XPS spectra, together with those predicted in the perfect mixing and complete chemically ordered cases. 
TABLE II. Peak position and FWHM (in eV) of the Gaussian components of the XPS C $1 s$ spectra.

\begin{tabular}{ccc}
\hline \hline Bond contribution & Peak & FWHM \\
\hline $\mathrm{C}-\mathrm{Si}$ & 283.0 & 1.6 \\
$\mathrm{C}-\mathrm{C}$ & 284.2 & 1.5 \\
\hline
\end{tabular}

The percentage of heteropolar bonds as a function of the composition of the $\mathrm{Si}_{1-x} \mathrm{C}_{x}$ alloy is plotted in Fig. 7, together with those corresponding to the perfect mixing and complete chemically ordered cases. Figure 7 , together with the previous ones, shows the existence of a partial chemical order in the $\mathrm{SiC}$ amorphous layer obtained by ion implantation into amorphous $\mathrm{Si}$. For the composition range 0.35 $<x<0.6$, there is a saturation of the percentage of heteropolar bonds at $70 \%$, in between the values expected for the complete chemically ordered case $(100 \%$ of heteropolar bonds for $x=0.5)$ and for the perfect mixing case $(50 \%$ of heteropolar bonds for $x=0.5$ ). This result agrees with that of Chehaidar et al. ${ }^{13}$ who reported the existence of a partial chemical order from the Raman scattering analysis of amorphous $\mathrm{Si}$ rich $\mathrm{SiC}$ films deposited by glow discharge. In this work, all the carbon atoms were bonded to $\mathrm{Si}$, forming with the $\mathrm{Si}-\mathrm{Si}$ bonds a tetrahedrally connected network. The lack of a complete chemical order was deduced from the presence of the $\mathrm{Si}-\mathrm{Si}$ and $\mathrm{C}-\mathrm{C}$ vibrational bands-in addition to the $\mathrm{Si}-\mathrm{C}$ related ones-at stoichiometric composition. The existence of an intermediate situation in between the complete chemical order and the complete mixing cases in amorphous stoichiometric $\mathrm{SiC}$ has also been theoretically predicted by Finocci et al. ${ }^{27}$ However, the experimental data presented in the present work suggest a higher degree of chemical order in the amorphous $\mathrm{SiC}$ alloy, obtaining a percentage of heteropolar bonds of about 70\%, which is higher than that simulated by Finocci et al. (of about 55-60\%).

On the other hand, Takeshita et al. ${ }^{12}$ have interpreted the XPS data from glow discharged amorphous SiC layers in terms of the complete chemical order with the homogeneous dispersion model (COHD). In this model, the spectra arise from five possible contributions corresponding to the different tetrahedral bonding configurations $\left(\mathrm{Si}-\mathrm{Si}_{4-n} \mathrm{C}_{n}\right.$ and $\mathrm{C}-\mathrm{C}_{4-n} \mathrm{Si}_{n}$ with $n=0-4$ ) averaged according to the different bond probabilities predicted for the different models indicated in Sec. I. ${ }^{11}$ A problem related to this fitting is the small energy difference between the contributions from consecutive tetrahedras, of the order of the energy resolution in the experimental measurements (about $0.2-0.3 \mathrm{eV}$ ). To solve this problem, Takeshita et al. adopted a weighted average method to fit the peak energies of the experimental spectra assuming a complete chemically ordered system. In this method, only the peak position of the spectra was taken into account. Although a good fitting was obtained for the peak position of the Si $2 p$ line, the data for the $\mathrm{C} 1 s$ line did not fit with the model, observing the presence of changes in the peak position of the C $1 s$ peak for Si rich layers-for which the model predicts the absence of $\mathrm{Si}-\mathrm{C}$ heteropolar bonds. To explain these data, the authors claimed the presence of

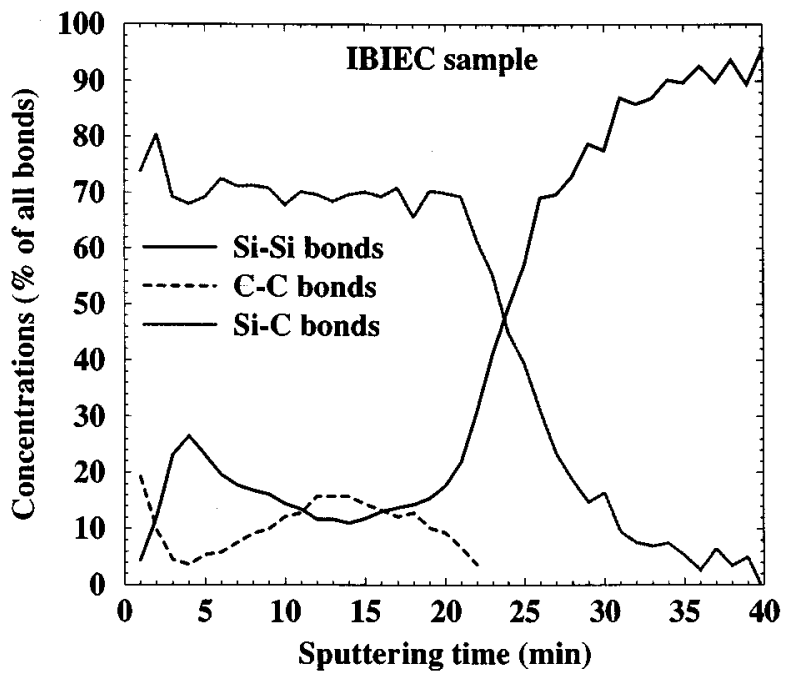

FIG. 8. Relative distribution profiles of $\mathrm{Si}-\mathrm{Si}, \mathrm{C}-\mathrm{C}$, and $\mathrm{Si}-\mathrm{C}$ bonds in the IBIEC processed sample vs sputter time, determined from the fitting of the XPS spectra.

induction effects and shifts in the Fermi levels affecting the position of the $\mathrm{C} 1 s$ line.

In our case all the spectra have been fitted to determine the different possible contributions. In principle, five possible contributions were considered in the fitting of the spectra. However, this fitting always led only to two significant contributions. The characteristics of these contributions are those indicated in Tables I and II. For the Si $2 p$ spectra, these contributions correspond to $\mathrm{Si}-\mathrm{Si}_{4}$ and $\mathrm{Si}-\mathrm{C}_{4}$. For the $\mathrm{C}$ $1 \mathrm{~s}$ spectra, and taking into account the data previously reported, ${ }^{9,14,19,26}$ the contribution at $283.0 \mathrm{eV}$ can be identified with $\mathrm{C}-\mathrm{Si}_{4}$. However, the second contribution (at 284.2 $\mathrm{eV}$ ) appears at an energy somehow lower than that assumed by Takeshita et al. for the $\mathrm{C}-\mathrm{C}_{4}$ one. ${ }^{12}$ This disagreement could be related to the high uncertainty related to this contribution, which is very small in almost all the spectra. Moreover, we have to remark that, in contrast with the previous data from Takeshita et al., ${ }^{12}$ the results obtained from the $\mathrm{Si}$ $2 p$ and $\mathrm{C} 1 s$ spectra show the same behavior, obtaining the same percentage of heteropolar bonds in both cases. The presence of only two significant contributions in the XPS spectra suggests the existence in our case of a tendency towards partial chemical ordering with phase separation.

By thermal annealing at $700{ }^{\circ} \mathrm{C}$, no significant changes are observed in the $\mathrm{C}$ implanted layer. The main change in the thermally annealed sample is the recrystallization of the Si region below the carbon implanted layer. This contrasts with the strong recrystallization of $\mathrm{SiC}$ by the IBIEC process. However, recrystallization is not complete, observing in the Raman spectra amorphous bands related to $\mathrm{Si}-\mathrm{Si}$ and $\mathrm{C}-\mathrm{C}$ vibrational modes.

Figure 8 shows the different bond contributions in the IBIEC processed sample, as obtained from the fitting of the XPS spectra. As can be seen, the distribution of bonds is very similar to that from the carbon as-implanted one. The similar amount of $\mathrm{Si}-\mathrm{C}$ bonds from the carbon as-implanted and IBIEC processed samples agrees with the fact that the FTIR 
absorption bands measured on these samples have the same area, as already indicated (see Fig. 1). The shape of the FTIR spectrum from the IBIEC processed sample points out that all $\mathrm{Si}-\mathrm{C}$ bonds are in crystalline phase. Then, according to the Raman spectra, homonuclear $\mathrm{C}-\mathrm{C}$ and $\mathrm{Si}-\mathrm{Si}$ bonds already present in the carbon as-implanted layer are not broken by the IBIEC process, remaining in an amorphous phase. Only in those regions with a dominant concentration of $\mathrm{Si}-\mathrm{C}$ bonds, these bonds are reorganized in a crystalline structure, forming the grains observed by TEM.

According to these data, the IBIEC process is not able to break the homonuclear bonds in the implanted layer, and no significant diffusion of $\mathrm{Si}$ or $\mathrm{C}$ atoms is observed. This behavior might be determined by the high stability of the $\mathrm{C}-\mathrm{C}$ bond, mainly in $s p^{2}$ coordination, being the energy of this bond very much higher than that of the $\mathrm{Si}-\mathrm{Si}$ or $\mathrm{Si}-\mathrm{C}$ ones (6.42 eV, in front of 2.35 and $3.21 \mathrm{eV}$, respectively). ${ }^{13} \mathrm{We}$ have to remark that the Raman spectrum in the $\mathrm{C}-\mathrm{C}$ region from the IBIEC processed sample shows a shape similar to that reported for amorphous graphitic carbon, which strongly suggests $\mathrm{C}-\mathrm{C}$ bonds in this sample to be in $s p^{2}$ coordination. ${ }^{13}$ Then, problems related to the recrystallization of the $\mathrm{SiC}$ amorphous phase are likely determined by the high stability of the $\mathrm{C}-\mathrm{C} s p^{2}$ bond.

\section{CONCLUSIONS}

In summary, the analysis of the amorphous $\mathrm{SiC}$ layer formed by carbon ion implantation onto amorphous $\mathrm{Si}$ shows the existence of a partially chemically ordered structure, with about $70 \%$ of heteropolar bonds. Moreover, the fitting of the XPS spectra measured at this layer suggests a partial phase separation, instead of homogeneous dispersion. By IBIEC, domains with dominant contribution of $\mathrm{Si}-\mathrm{C}$ bonds recrystallize, remaining as amorphous residual material those with homopolar $\mathrm{Si}-\mathrm{Si}$ and $\mathrm{C}-\mathrm{C}$ bonds (these last in $s p^{2}$ coordination). These data suggest the high stability of amorphous $\mathrm{SiC}$ to be related to the absence of a complete chemical order.

\section{ACKNOWLEDGMENTS}

This work was partially funded by Spanish CICYT under Project Ref. No. MAT92-0351 and by Spanish-German Cooperation Programme "Acciones Integradas HispanoAlemanas" (Ref. No. HA-121). This work was also sup- ported by the E-MRS Network III and IBOS Network of the HCM programme of the CEC (Contract No. ERBCHRXCT93-0125).

${ }^{1}$ H. Morkoç, S. Strite, G. B. Gao, M. E. Lin, B. Sverdlov, and M. Burns, J. Appl. Phys. 76, 1363 (1994).

${ }^{2}$ P. G. Neudeck, J. Electron. Mater. 24, 283 (1995).

${ }^{3}$ G. Müller, G. Krötz, and E. Niemann, Sensors Actuators A 43, 259 (1994).

${ }^{4}$ A. Arbab, A. Spetz, and I. Lundström, Sensors and Actuators B 18-19, 562 (1994).

${ }^{5}$ H. G. Bohn, J. M. Williams, C. J. McHargue, and G. M. Begun, J. Mater. Res. 2, 107 (1987).

${ }^{6}$ J. A. Edmond, R. F. Davis, and S. P. Withrow, Ceram. Trans. 2, 479 (1989).

${ }^{7}$ C. J. McHargue and J. M. Williams, Nucl. Instrum. Methods Phys. Res. B 80/81, 889 (1993).

${ }^{8}$ V. Heera, J. Stoemenos, R. Kögler, and W. Skorupa, J. Appl. Phys. 77, 2999 (1995)

${ }^{9}$ E. Ech-chamikh, E. L. Ameziane, A. Bennouna, M. Azizan, T. A. Nguyen Tan, and T. Lopez-Rios, Thin Solid Films 259, 18 (1995).

${ }^{10}$ Ch. Wagner, G. Krötz, H. Sonntag, H. Möller, G. Müller, and S. Kalbitzer, 8th International Conference on Solid-State Sensors and Actuators (TRANSDUCERS'95) and EUROSENSORS IX, Stockholm, Sweden, June 1995, p. 186.

${ }^{11}$ K. Mui and F. W. Smith, Phys. Rev. B 35, 8080 (1987).

${ }^{12}$ T. Takeshita, Y. Kurata, and S. Hasegawa, J. Appl. Phys. 71, 5395 (1992).

${ }^{13}$ A. Chehaidar, R. Carles, A. Zwick, C. Meunier, B. Cros, and J. Durand, J. Non-Cryst. Solids 169, 37 (1994).

${ }^{14}$ W. Y. Lee, J. Appl. Phys. 51, 3365 (1980).

${ }^{15}$ Y. Katayama, K. Usami, and T. Shimada, Philos. Mag. B 43, 283 (1981).

${ }^{16}$ A. Sproul, D. R. McKenzie, and D. J. H. Cockayne, Philos. Mag. B 54, 113 (1986).

${ }^{17}$ A. E. Kaloyeros, R. B. Rizk, and J. B. Woodhouse, Phys. Rev. B 38, 13099 (1988).

${ }^{18}$ C. Meneghini, S. Pascarelli, F. Boscherini, S. Mobilio, and F. Evangelisti, J. Non-Cryst. Solids 137/138, 75 (1991).

${ }^{19}$ N. Laidani, R. Capeletti, M. Elena, L. Guzman, G. Mariotto, A. Miotello, and P. M. Ossi, Thin Solid Films 223, 114 (1993).

${ }^{20}$ J. F. Ziegler, J. P. Biersack, and U. Littmark, The Stopping and Range of Ions in Solids (Pergamon, New York, 1985), Vol. 1.

${ }^{21}$ J. Pezoldt, B. Stottko, G. Kupris, and G. Ecke, Mater. Sci. Eng. B 29, 94 (1995).

${ }^{22}$ J. Bullot and M. P. Schmidt, Phys. Status Solidi B 143, 345 (1987).

${ }^{23}$ A. Pérez-Rodríguez, C. Serre, L. Calvo-Barrio, A. Romano-Rodríguez, J. R. Morante, Y. Pacaud, R. Kögler, and W. Skorupa, Proc. SPIE 1995, edited by S. V. Svechnikov and M. Ya. Valakh, Vol. 2648, p. 481.

${ }^{24}$ L. R. Doolittle, Nucl. Instrum. Methods B 9, 344 (1985).

${ }^{25}$ C. Serre, A. Pérez-Rodríguez, A. Romano-Rodríguez, J. R. Morante, R. Kögler, and W. Skorupa, J. Appl. Phys. 77, 2978 (1995).

${ }^{26}$ R. C. Lee, C. R. Aita, and N. C. Tran, J. Vac. Sci. Technol. A 9, 1351 (1991).

${ }^{27}$ F. Finocci, G. Galli, M. Parrinello, and C. M. Bertoni, Phys. Rev. Lett. 68, 3044 (1992). 